\title{
Fibre in the management of diabetes
}

\author{
1 Natural fibre useful as part of total dietary prescription \\ 1 T D R Hockaday
}

Producing a universally accepted definition of dietary fibre $^{12}$ or measuring it precisely ${ }^{2+}$ are small problems beside general unawareness of the different actions of the two main types of fibre. The two types are best described as insoluble or fibrous - for example, bran-and gel forming, viscous, or soluble, according to how they mix with water. Viscous fibre includes the storage carbohydrates of legumes - for example, galactomannans such as guar flour - and pectins of fruit, but it is also found in cereals (oats) and green vegetables (okra).

\section{Properties of viscous fibre}

Viscous fibre affects the body's metabolism by its actions within the stomach and small bowel, whereas insoluble fibre hardly does so at all, except perhaps for a slight effect on energy intake through reducing the energetic density of what is eaten; however, it certainly eases bowel habit. Both types are liable to colonic fermentation and the important production of extremely short chain fatty acids.

Viscous fibre reduces postprandial increases in plasma glucose and insulin concentrations in normal and diabetic subjects, ${ }^{6-}$ and in proportion to the viscosity of their aqueous mixture. ${ }^{x}$ Indeed, synthetic resins such as cholestyramine share many of their properties, particularly that of lowering plasma cholesterol concentration including the low density lipoprotein fraction. ${ }^{910}$ This probably depends mostly upon altered circulation of bile salts" as fat absorption is reduced only slightly. "2 The glucose-insulin effect is based on a reduced rate of gastric emptying ${ }^{13}$ and small bowel motility; the rate of absorption, from the small intestine is reduced because viscous contents mix less well and the watery "clear" layer, into which the villi pump to and fro, is thinned. ${ }^{1+}$ This was established for guar in particular by measuring breath hydrogen and urinary xylose elimination."

These actions were maintained over months if 15$20 \mathrm{~g}$ guar flour was used daily in divided doses, ${ }^{16}$ and they have been successfully shown by Simpson et al for wholefoods rather than pharmacological concentrates of viscous fibre. ${ }^{118}$ Diabetic patients whether or not they were treated with insulin showed improved glycaemic control (by 15\%) and lipid values (by 14\%), with reduction in total and low density lipoprotein cholesterol concentrations and the ratio of low to high density lipoprotein. To obtain such effects it seems necessary to take at least $35 \mathrm{~g}$ fibre daily, with a high percentage (about $50 \%$ or perhaps $18-20 \mathrm{~g}$ ) being of the viscous type. ${ }^{16-19}$ The glycaemic action affects the fasting as well as the postprandial values, ${ }^{18}$ but this is not always easy to separate from the lowering of fasting

\section{.. High fibre diets are effective in children and have been used from the Arctic to the Mediterranean.}

glucose concentration when the total percentage of carbohydrate increases. There may also be a "second meal" effect through which the glycaemic response to a second meal may be reduced if viscous fibre is included in a meal eaten four hours previously, perhaps because the systems dealing with absorbed food are still more active than when absorption ended earlier. ${ }^{20}$ The delay in absorption is also illustrated in the slightly higher glucose and insulin values seen several hours after a meal containing viscous fibre. ${ }^{6}$ Reports of reduced hypoglycaemia in patients treated with insulin and of lessening of reactive hypoglycaemia are anecdotal rather than systematic.

\section{High fibre diets}

Three British papers have claimed an inadequacy of high fibre diets among diabetic patients. Two from Nottingham $^{2122}$ have been widely criticised, 23.25 essentially for lack of appreciation of the different types of fibre and because both diets were high in fat. The Sheffield study ${ }^{26}$ may well not have been analysed to look best for an effect of fibre. As always with prolonged studies on subjects in the community, compliance is questionable. The belief that patients from Nottingham were unable to eat a high fibre diet ${ }^{2}$ is surely wrong; but maybe they won't. What happens in families can depend on the grandmothers' opinions, so the sooner the dietetic education of children is better the sooner will grandmothers be better informed. High fibre diets are effective in children ${ }^{28}$ and have been used from the Arctic ${ }^{24}$ to the Mediterranean. ${ }^{21}$
Sheikh Rashid Diabetes Unit, Radcliffe Infirmary, Oxford OX2 6HE

T D R Hockaday, FRCP, director

Br.Hed 7 1990;300:1334-6

\section{EDITORIAL COMMENT}

Reading these articles brought to mind a controversy in subject closer to my own interests concerning salt and blood pressure. I think few would argue with the premise that a diet free of all salt will lead to modest reductions in blood pressure, but equally most people would agree that such diets are basically unpalatable. Similarly, in the case of fibre and diabetes the evidence that fibre such as guar can improve diabetic control seems indisputable. As this fibre needs to be a constituent of the diet, however, the real controversy is not about efficacy but compliance. Surely this all comes down to patient choice and preference? The advantages and disadvantages of a diet high in viscous fibre should be clearly explained to the patient, who then has the option of embarking along this route. Again a similarity with hypertension is striking-I always encourage my hypertensive patients who are obese to lose weight with the prospect that they may well avoid drug treatment should they succeed. Regrettably, most don't lose weight and it may well be that fibre diets in diabetes fall into the same category. But it would be a great pity to discount them out of hand.-PETER C RUBIN, professor of therapeutics, University of Nottingham 
The inevitable interrelations of dietary constituents complicate interpretation in terms of both the percentage of ingested calories and interactions within the gut. It is difficult to design a high fibre diet (without pharmacological fibre) that is not rich in carbohydrate (and low in fat) as well as comparatively rich in plant food. Increased dietary intake of carbohydrate usually lowers fasting glycaemia and improves glucose tolerance (provided that the supply of insulin is adequate), but, overall, glycaemia may deteriorate and plasma triglyceride concentration rise, at least during the first six months after the change. Coulston et al observed this when dietary carbohydrate rose from $40 \%$ to $60 \%$ of total energy intake but fibre (mainly fibrous) increased only from $26 \mathrm{~g}$ to $36 \mathrm{~g}$ daily. ${ }^{3 !}$ Such observations make all the more impressive the lowered glucose concentrations achieved when viscous fibre is allied with increased carbohydrate content.

Other dietary factors confound interpretation. The glycaemic response to food is affected by how it is prepared and cooked, how much water accompanies it, and the chemical nature of its carbohydrate, let alone the extent to which it is encased in cell walls that can be broken down only slowly. Similarly, the lipaemic benefits of viscous fibre have at times been enhanced by a coincident increase in dietary polyunsaturated fat, ${ }^{17}$ just as monounsaturated fat (compared with saturated fat) mav affect the lipid response to increased (low in fibre) carbohydrate. ${ }^{32}$ There is no evidence however, of the development of mineral deficiency, even when viscous fibre has been used for a year. ${ }^{16}$

\section{Conclusions}

Any summary recommendation must entail a total dietary prescription (it should really be through recipes $^{33}$ ) rather than advice as to single dietary constituents. Some dietary regimens are listed in a recent article by Anderson et al in America ${ }^{34}$ and in the table, whose basis depends on $(a)$ the improved glycaemic, lipaemic, and insulinaemic values repeatedly found when the increase in viscous fibre is pronounced; $(b)$ the belief that these changes will reduce diabetic tissue damage, particularly the predominant macroangiopathy; $(c)$ the repeated concern that low carbohydrate diets are high in fat and so likely to be arteriosclerotic $^{35}{ }^{36}$; and $(d)$ knowledge, not least from the Third World, that diets high in carbohydrate do not inevitably worsen glycaemia. ${ }^{37}$ The benefits from high fibre intake are not massive but may improve control that is otherwise only fairly good. Such benefits are augmented (particularly in terms of lipid concentrations) by other recent dietary notions - for example, increasing the percentage of unsaturated fats.

Is fibre best given as a constituent of foods in which it occurs naturally, or almost pharmacologically as available concentrates - for example, guar? The initial difficulties in preparing palatable concentrates have been largely overcome (though pronounced individual differences persist about how slimy a highly viscous food is thought to be). None the less, the associated

Diet, exercise, and body mass index in four types of people

\begin{tabular}{lcccc}
\hline & Ignorant rich & Long term ideal & Baffled poor & Diabetics trying hard \\
\hline Energy intake & High & Low & Medium & Medium \\
Composition of energy $(\%):$ & & & & \\
$\quad$ Carbohydrate & 35 & 55 & 40 & 45 \\
$\quad$ Fat & 45 & 30 & 30 & 15 \\
$\quad$ Saturated & 40 & $22^{\star}$ & 10 & $20^{\star}$ \\
$\quad$ Unsaturated & 5 & 50 & $<12$ & 36 \\
Fibre $(\mathrm{g} /$ day) & $<12$ & $>18$ & $<3$ & 15 \\
$\quad$ Total & $<3$ & High & Low & Medium \\
$\quad$ Viscous & Low & $<25$ & $28-32$ & $<27$ \\
Body mass index $\left(\mathrm{kg} / \mathrm{m}^{2}\right)$ & $>30$ & & & \\
\hline
\end{tabular}

*Half is monounsaturated fat. alimentary symptoms of distension, fullness, borborygmi, and flatulence may remain a problem, but one largely mitigated by the gradual introduction of viscous fibre into the diet over several weeks. The symptoms always noticeably lessen after three or four months of eating the diet once gut function and villus structure have adapted. The advantages of eating natural fibre reside in the simultaneous avoidance of possibly injurious diet - for example, saturated fats or quickly digested carbohydrate in excess - and the fact that, almost inevitably, such fibre will be eaten with slow release carbohydrate.

1 Trowell H, Godding E, Spiller G, Briggs G. Fiber bibliographies and erminology. Am . C Clin Nutr 1978;31:1489-90.

2 Southgate DAT. Definition and terminology of dietary fiber. In: Vahouny GA. Kritchersky D, eds. Dietary fiber in health and disease. New York: Plenum 1982:1-7

3 Prosky L. Analysis of total dietary fiber: the collaborative study. In: Vahouny GA, Kritchevsky D, eds. Dietary fiber: basic and clinical aspects. New York: Plenum, 1986:1-16

4 Englyst HN, Cummings JH. Measurement of dietary fiber as nonstarch polvsaccharides. In: Vahouny GA, Kritchersky D, eds. Dietary fiber: basic and clinical uspects. New York: Plenum, 1986:17-34.

5 Chen WJL, Anderson JW, Jennings D. Propionate may mediate the hypocholesterolemic effects of certain soluble plant fibers in cholesterol-fed rats. Proc Soc Exp Biol Med 1984;175:215-8.

6 Gassull MA, Goff DV, Haismann P, et al. The effect of unavailable carbohydrate gelling agents in reducing post-prandial glycaemia in normal carbohydrate gelling agents in reducing post-prandial glyca

7 Jenkins DJA, Goff DV, Leeds AR, et al. Unabsorbable carbohydrates and diabetes: decreased post-prandial hyperglycaemia. Lancet 1976;ii: 172-4

8 Jenkins DJA, Wolever TMS, Leeds AR, et al. Dietary fibres, fibre analogues. and glucose tolerance: importance of viscosity. Br.Med f 1978;i:1392-4.

9 Luyken R, de Wijn JF, Pikaar NA, Van der Meer R. De invloed van havermont op het serum cholesterolgehalte van het bloed. Voeding 1965; 26:229-44

10 Grande F, Anderson JT, Keys A. Effect of carbohydrates of leguminous seeds, wheat and potatoes on serum cholesterol concentration in man. $7 \mathrm{Nut}$ 1965;86:313-7.

11 Jenkins DJA, Leeds AR, Newton C, Cummings JH. Effects of pectin, guar gum and wheat fibre on serum cholesterol. Lancet 1975;i:1116-7.

12 Vahouney GV. Dietary fiber and intestinal absorption of lipids. In: Vahounes GV, Kritchersky D, eds. Dietary fiber in health and disease. New York: Plenum, 1982:203-27.

13 Holt S, Heading RC, Carter DC, Prescott LF, Tothill P. Effect of gel fibre on gastric emptying and absorption of glucose and paracetamol. Lancet $1979 ; i: 636-9$.

14 Elsenhaus B, Sufke U, Blume R, Caspary WF. The influence of carbohydrate gelling agents on rat intestinal transport of monosaccharides and neutra amino acids in vitro. Clin Sci 1980;59:373-80.

15 Jenkins DJA, Leeds AR, Gassull MA, Cochet B, Alberti KGMM. Decrease in post-prandial insulin and glucose concentrations by guar and pectin. Ann Intern Med 1977:86:20-3.

16 Jenkins DJA, Wolever TMS, Taylor RH, Revnolds D, Nineham R, Hockaday TDR. Diabetic glucose control, lipids, and trace elements on long-term guar. Br Med f 1980;280:1353-4.

17 Simpson RW, Mann JI, Eaton J, Moore RA, Carter R, Hockaday TDR. Improved glucose control in maturity onset diabetes treated with high carbohydrate, modified fat diet. Br Med f 1979;i:1753-6.

18 Simpson HCR, Simpson RW, Lousley S, et al. A high carbohydrate, leguminous fibre diet improves all aspects of diabetic control. Lancet leguminous

19 Karlstrom B, Vesspy B, Asp NG, Bobery M, Litthall H, Berne C. Effects of leguminuous seeds in a mixed diet in non-insulin dependent diabetic patients. Diubetes Res 1987;5:199-205.

20 Jenkins DJ. Wolever TM, Nineham R, et al. Improved glucose tolerance 4 hours after taking guar with glucose. Diabetologia 1980;19:21-4

21 McCulloch DK, Mitchell RD, Ambler J, Tattersall RB. The prospective comparison of "conventional" and high carbohydrate/high fibre/low fat diets in adults with established type I (insulin-dependent) diabetes. Diabetologia $1985 ; 28: 208-12$

22 Scott AR, Attenborough Y, Peacock I, Fletcher E, Jeffcoate WJ, Tattersall RB. Comparison of high fibre diets, basal insulin supplements, and flexibl insulin treatment for non-insulin dependent (type II) diabetics poorly controlled with sulphonylureas. Br Med F 1988;297:707-10.

23 Hockaday TDR, Mann JI. "Conventional" and high carbohydrate/high fibre/ low fat diets in adults with established type I (insulin-dependent) diabetes. Diabetologia 1985;28:793.

24 Hockaday TDR. Diabetes poorly controlled by sulphonylureas. Br Med $\mathcal{Y}$ 1988;297:1197.

25 Mann JI, Chisholm A, Milne R. Diet and diabetes revisited. $\mathrm{Br} \mathrm{Med} \mathcal{J}$ 1988:297:1406.

26 Beattie VA, Edwards CA, Hosker JP, Callan DR, Ward JD, Read NW. Does adding fibre to a low energy, high carbohydrate, low fat diet confer any benefit to the management of newly diagnosed, overweight, type II diabetes? Br Med J 1988:296:1147-9.

27 Scott AR. Diabetes poorly controlled by sulphonylureas. Br Med f 1988 297:1197

28 Kinmonth A-L, Angus RM, Jenkins PA, Smith MA, Baum JD. Whole foods and increased dietary fibre improve blood glucose control in diabetic children. Arch Dis Child 1982;57:187-94.

29 Aro A, Uusitupa M, Voutilainen E, Hersio K, Korhonen T, Siitonen 0 . Improved diabetic control and hypocholesterolaemic effect induced by longterm dietary supplementation with guar gum in type II (insulin-dependent diabetes. Displementation with g ar

30 Riccardi G, Rivellese A, Pacioni D, Genovese S, Mastranzo P, Mancini M. Separate influence of dietary carbohydrate and fibre on the metabolic control in diabetes. Diabetologia 1984;26:116-21.

31 Coulston AM, Hollenbeck CB, Swislockt ALM, Chen Y-DI, Reaven (iM. 
Deleterious metabolic effects of high-carbohydrate, sucrose-containing diets in patients with non-insulin-dependent diahetes mellitus. A $m$ f. Med 1987;82:213-20.

32 Garg A, Bonanone A, Grundy SM, Zhang Z-J, Unger RH. Comparison of a high carbohydrate diet with a high monounsaturated-fat diet in patients with non-insulin-dependent diabetes mellitus. Y Fngl f Mcd 1988:319:829-34. 33 Mann JI, Longstaff R. The diabetics' cookbook. Positive health guide. London:

34 Anderson JW', Bridges SR, Tietsen J, Gustafsen NJ. Dietarv fibre content of a simulated American diet and selected research diet. Am 7 cilm Nutr 1989:49:352-7.

35 Rabinowitch I.1. Arteriosclerosis in diabetics: relationship hetween plasma cholesterol and arteriosclerosis and effects of the high carbohydrate. fow caloric dict. Ann Intern. Hed 1935:8:1+36-74.

36 Albrink MJ, Larietes PH, Man AB. Vascular disease and serum lipids in

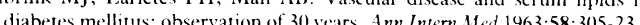

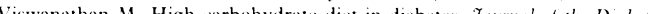
Association of India 1968:8:853.

\section{2 Benefits of fibre itself are uncertain Robert Tattersall, Peter Mansell}

A former dean of the Harvard Medical School is said to have told students at graduation, "Half of what we have taught you is wrong. Unfortunately, we don't know which half!'” The diet for non-insulin dependent diabetes is a case in point. Many doctors were taught simplistically that too much glucose in the blood could be treated only by eating as little carbohydrate as possible. They therefore prescribed low carbohydrate diets that were high in fat as this was the only affordable way of making up the energy. Currently, most diabetes associations, including the British Diabetic Association, ${ }^{2}$ recommend high carbohydrate, high fibre, low fat diets for all diabetics, although this is tempered by the advice that "any dietary strategy - for example, calorie counting, slimming clubs, etc- which reduces energy intake in the obese non-insulin dependent diabetic is acceptable if it is nutritionally sound."

We agree that many patients with non-insulin dependent diabetes are hyperlipidaemic ${ }^{2}$ and that this may contribute to their exorbitant rates of arterial disease. It is also a reasonable premise that eating less saturated fat will be beneficial and this is best achieved by a reciprocal increase in dietary carbohydrate. Nevertheless, diets high in carbohydrate and fibre raise the same questions as any other innovation in treatment. Do they work and, even if they do, will people follow them?

\section{History of high fibre diets and diabetes}

High carbohydrate diets for diabetes have been in vogue intermittently for over 100 years. For example, in the early 1900s van Noorden's "oat cure" was greeted as an astounding and mysterious phenomenon and followed by much wasted effort to show the superiority of oatmeal over other carbohydrates (a foretaste of the minutiae of the glycaemic index). The fibre story began in 1880 when Dr T R Allinson (whose $100 \%$ stoneground wholemeal flour is still available) wrote, "One great curse of this country is constipation, which is caused in great measure by white bread. From this constipation come piles, varicose veins, headaches, miserable feelings, dullness and other ailments." ${ }^{\prime \prime} \mathrm{Dr}$ Allinson was struck off the medical register, and only in the late 1960s was his idea that Western diseases are due to a deficiency of dietary fibre resurrected by Cleave, Burkitt, and Trowell. Their hypothesis that the excess of constipation, appendicitis, cancer of the colon, and diabetes in Europeans compared with Africans was due to a deficiency of dietary fibre is now well accepted, although the epidemic of diabetes in developing countries is probably a multifactorial process in which genes, lack of exercise, and obesity are as or more important than a deficiency of fibre.

Even if a lack of fibre does cause diabetes, however, it does not necessarily follow that eating it in normal or excessive quantities will be beneficial in treating the established disease. In the mid-1970s Jenkins et al in Oxford showed that adding the unabsorbable polysaccharides guar and pectin reduced postprandial blood glucose concentrations in both normal and diabetic people, with a flattening of the insulin response in the controls and a need for less insulin in the diabetic subjects. ${ }^{5}$ Not all fibres were equal. Highly viscous ones (such as guar) worked best, gum tragacanth and methylcellulose were less effective, and pectin and bran were unimpressive. To reduce blood glucose concentra-

\section{... The glycaemic response to a particular food correlates only weakly with the total fibre content.}

tions the fibre had not only to be viscous but also to be incorporated into the food-giving it as a capsule, sprinkling it on the food, or taking it before a meal did not work. This differential effect of various fibres and the difficulty in defining exactly what is being fed to patients have led to many problems. It is easy to define fibre as "components of plant material which resist human digestive enzymes," but life becomes difficult when we are warned that

Fibre-rich foods contain a variety of fibres and the effects of each cannot be determined using natural foods. On the other hand, when fibres are extracted from natural foods, their actions may not resemble those of the same fibres when fed as an integral part of the intact food. The fibre-nutrient relationship in foods is disrupted by cutting, cooking and chewing...."

For simplicity we can say that insoluble fibre-for example, wheat bran-speeds up intestinal transit, increases faecal bulk, and is good for the bowels, whereas soluble fibre (such as guar) gums you up, delays gastric emptying, and may lower blood glucose concentrations. The glycaemic response to a particular food correlates only weakly with the total fibre content ${ }^{3}$ and may have more to do with the chemical and mechanical forms in which the carbohydrate is held. ${ }^{*}$

\section{Clinical trials of high fibre diets}

The earliest clinical trials of high fibre diets were performed in the late 1970s, and one English and one American study were particularly influential. In Oxford a six week crossover study in 18 patients with noninsulin dependent diabetes compared a standard low carbohydrate diet with a "high carbohydrate diet containing leguminous fibre." Most of the patients were taking sulphonylureas and their glycaemic control was already good with the low carbohydrate diet; their mean fasting blood glucose concentration of $6.7 \mathrm{mmol} / 1$ was reduced to $5.7 \mathrm{mmol} / \mathrm{l}$ by the test diet. What was not fully appreciated by many was that the daily provision of fibre in the test diet was a massive $96.6 \mathrm{~g}$, of which " $64 \%$ was derived from leguminous sources, most of the remainder being cereal fibre in the form of wholemeal bread . . . beans were consumed twice daily, usually at breakfast and supper." In retrospect, it was unclear whether the improved diabetic control (such as
Peter Mansell, MRCP registrar
BMJ VOLUME 300

19 MAY 1990 